\title{
Metamorfose cálcica da polpa e necrose pulpar asséptica no planejamento ortodôntico
}

\author{
Alberto Consolaro*, Vanessa da Rocha Bernardini**
}

O significado de alguns sinais imaginológicos deve ser esclarecido no planejamento ortodôntico. Após a anamnese e exame clínico do paciente, por alguns minutos ou horas, analisaremos os exames complementares solicitados ao paciente, uma vez formuladas nossas hipóteses de diagnóstico clínico. Entre estes exames complementares destacam-se os modelos, as radiografias extrabucais e, especialmente, as radiografias periapicais de todos os dentes.

Entre os principais sinais imaginológicos estão a forma da raiz, a morfologia do ápice radicular, a proporção coroa-raiz e a morfologia da crista óssea alveolar. Estes sinais são importantes na elaboração do Planejamento Defensivo para as reabsorções radiculares durante o tratamento ortodôntico. Estes sinais estão inevitavelmente presentes nas radiografias periapicais, mas alguns aparecem apenas eventualmente, como as faturas dentárias, as reabsorções radiculares, as dilacerações e a obliteração da câmara pulpar e/ou do canal radicular, também referida de forma mais apropriada como Metamorfose Cálcica da Polpa.

A polpa dentária não envelhece estruturalmente pela aplicação de um tratamento ortodôntico. O envelhecimento pulpar também não revela relação direta ou indireta com a idade cronológica do paciente e está diretamente relacionado com fatores ambientais como atrição, abrasão, erosão, abfração, traumatismos, cáries e procedimentos restauradores. A doença periodontal, por sua vez, não tem se apresentado como uma eficiente envelhecedora pulpar.

Quando submetidos a traumatismos, os dentes podem sofrer fraturas ou não. Independentemente da ocorrência de fraturas dentárias em seus variados graus de comprometimento, o feixe vascular e nervoso no forame apical pode ser comprometido ou não. Em outras palavras, a polpa dentária pode ou não sofrer comprometimento do seu suprimento sanguíneo. Por um lado, o dente após o traumatismo pode permanecer com a polpa normal, por outro lado, em muitos casos ocorre a necrose pulpar.

A necrose pulpar por rompimento ou lesão do feixe vascular e nervoso no forame apical promove a desnaturação protéica, caracterizada pela perda de água, e as células pulpares ficam mantidas no local em seu arcabouço, mas coaguladas e sem vida. As células da polpa são pobres em lisossomos, organelas carregadas de enzimas proteolíticas. Este tipo de necrose também é referenciado como necrose por coagulação e pode ocorrer em várias partes do corpo, especialmente em áreas enfartadas e pobres em lisossomos. Em dentes traumatizados, com rompimento do feixe vascular e nervoso, mas que permaneceram estruturalmente hígidos, sem exposição da dentina e/ou polpa ao meio bucal e sem comprometimento periodontal, a necrose por coagulação representa o infarto pulpar e também é denominada de necrose asséptica.

Ao longo do tempo, os produtos do tecido pulpar necrosado podem se incorporar na estrutura dentinária e, geralmente, a decomposição protéica gera componentes escurecidos e o dente vai assumindo uma cor amarelada escurecida, com várias tonalidades. Radiograficamente, os limites pulpares na câmara e no canal radicular estão mantidos e os espaços pulpares com dimensões normais. Afinal, a

\footnotetext{
* Professor Titular de Patologia da FOB-USP. Professor de Pós-Graduação na FOB e FORP-USP.

** Ortodontista e pós-graduanda no Programa de Odontopediatria da Faculdade de Odontologia de Ribeirão Preto, Universidade de São Paulo (FORP - USP).
} 
polpa não teve tempo de depositar novas camadas de dentina reacional, pois a morte celular foi súbita. No periápice de dentes com necrose pulpar por coagulação ou asséptica, típica de traumatismos dentários, pode-se identificar pericementite apical crônica ou lesão periapical crônica sugestiva de granuloma periapical (Fig. 1). São lesões discretas, de longa duração e praticamente assintomáticas. $\mathrm{O}$ principal motivo de procura do profissional ou de queixa por parte do paciente refere-se à coloração alterada escurecida da coroa dentária.

Em síntese, quando um traumatismo ocorre e o dente permanece estruturalmente hígido, a polpa pode permanecer saudável ou evoluir para a necrose asséptica ou por coagulação, se o feixe vascular e nervoso foi severamente comprometido.

Mas o feixe vascular e nervoso pode ser apenas parcial ou transitoriamente comprometido. As células da polpa podem ser submetidas à hipóxia passageira, perda temporária de nutrientes e reduzir seu metabolismo ao mínimo necessário para a sobrevivência celular.

Uma das formas de adaptação celular a condições adversas é a metaplasia celular. A célula madura se transforma, muda seu fenótipo para um outro tipo celular igualmente maduro de célula e da mesma linhagem embrionária. A metaplasia representa uma forma eficiente de adaptação celular. Quando o indivíduo começa a fumar, as células de revestimento da traquéia e dos brônquios mudam de células epiteliais ciliadas e mucosas, cilíndricas, e grandes produtoras de muco, para células epiteliais escamosas e estratificadas, às vezes produzindo, inclusive, queratina superficial. Enfim, a metaplasia representa uma metamorfose na morfologia e função celular.

Na polpa de dentes traumatizados e que permaneceram estruturalmente hígidos, mas com lesão parcial do feixe vascular e nervoso, as células pulpares podem sofrer metaplasia para se adaptarem à hipóxia passageira e redução do metabolismo. Esta metaplasia leva os fibroblastos, os pericitos, as células indiferenciadas ou células-tronco teciduais, os pré-odontoblastos e até as células vasculares a se diferenciarem, modificarem ou se transformarem em odontoblastos, que iniciam uma produção aleatória e desorganizada de dentina reacional, com células e vasos incluídos em sua estrutura, a ponto de ser identificada até como osteodentina ou vasodentina. A osteodentina e a vasodentina são formas primitivas de dentina e encontradas como parte de dentes de animais inferiores na escala biológica evolutiva da vida animal.

Este depósito aleatório de dentina displásica, ou seja mal formada, geralmente é muito desorganizado e pouco mineralizado e pode até ter um direcionamento da periferia para o centro da polpa, mas nem sempre. Com freqüência, esta aleatoriedade de deposição de dentina displásica é absoluta e descontrolada. Após três meses, radiograficamente pode se notar apagamento dos limites pulpares normais, redução do volume pulpar, fechamento dos espaços pulpares na câmara e/ou no canal radicular (Fig. 1). O fechamento pode se completar com o apagamento dos espaços pulpares entre 6 meses e 1 ano após o traumatismo. Este fenômeno, muito conhecido e freqüente, também é simplesmente conhecido como Obliteração Pulpar, mas deveria ser mais apropriadamente identificado como Metamorfose Cálcica da Polpa, o nome mais utilizado na literatura pertinente sobre o assunto.

Clínica e radiograficamente a presença de Metamorfose Cálcica da Polpa indica história pregressa de traumatismo dentário. Dentes traumatizados quando movimentados ortodonticamente têm mais chances de apresentarem reabsorções radiculares mais severas, pois iniciam-se mais precocemente que os demais dentes.

Clinicamente, os dentes portadores de Metamorfose Cálcica da Polpa gradativamente adquirem uma coloração mais amarelada, inicialmente sutil, mas perceptível e incomodativa à medida que progride no tempo, chegando a severos escurecimentos coronários. A maior espessura dentinária e a forma de desorganização com que a dentina displásica é depositada deixam o esmalte translu- 
zir uma tonalidade bem escura e amarelada.

Em muitos casos o profissional instala o aparelho ortodôntico, movimenta o dente com Metamorfose Cálcica da Polpa, a reabsorção radicular mostra-se acentuada neste dente portador, o dente sofre escurecimento coronário e o paciente procura outro profissional e o veredicto diagnóstico inadequada e infelizmente poderá ser: o tratamento ortodôntico induziu necrose pulpar, reabsorção acentuada, obliteração pulpar e, em conseqüência, o escurecimento coronário! $\mathrm{Na}$ verdade o diagnóstico deveria ser: Metamorfose Cálcica da Polpa por traumatismo dentário anterior e Reabsorção Radicular acentuada induzida pelo tratamento ortodôntico. Houve falta de um planejamento defensivo para reabsorções radiculares, a partir das radiografias periapicais de todos os dentes, determinante para uma boa prática ortodôntica.

O diagnóstico da Metamorfose Cálcica da Polpa pode ser feito clinicamente a partir do escurecimento isolado de um ou dois dentes hígidos. $\mathrm{O}$ paciente pode até não recuperar a história de traumatismo dentário, mas ele ocorreu quase que inevitavelmente. $\mathrm{Na}$ radiografia periapical a obliteração do canal pelo apagamento de seus limites determinará o diagnóstico final. Mas não será surpresa se no lugar da Metamorfose Cálcica da Polpa, os limites pulpares estiverem preservados e o dente escurecido, associados a uma lesão periapical crônica, um quadro indicativo de necro- se pulpar asséptica por traumatismo com lesão severa ou rompimento do feixe vascular e nervoso no forame apical (Fig. 1).

As condutas a serem adotadas, nos casos de necrose pulpar asséptica ou por coagulação em dentes estruturalmente hígidos e nos casos de Metamorfose Cálcica da Polpa, envolvem imediata e diretamente o endodontista. A abordagem endodôntica será, no tempo, inevitável, quer seja via canal ou via cirúrgica paraendodôntica. O mesmo ocorrendo com o esteticista, que poderá ser requisitado visando a clareação dentária ou a colocação de facetas. A Metamorfose Cálcica da Polpa é progressiva, escurece a coroa e em $25 \%$ dos casos evolui com o tempo para lesão periapical crônica.

Neste insight, a inquietação advém das seguintes perguntas, cujas respostas não são encontradas na literatura pertinente:

1) Em uma casuística documentada com radiografias periapicais de todos os dentes, utilizadas nos planejamentos ortodônticos, qual a freqüência da Metamorfose

\section{Cálcica da Polpa?}

2) Quantos casos foram previamente diagnosticados nos planejamentos ortodônticos realizados?

3) Qual foi o protocolo de conduta mais adotado pelo ortodontista frente a este diagnóstico?

\section{Endereço para correspondência}

Alberto Consolaro

E-mail: alberto@fobusp.br 